Revista Matemática Universitária, vol. 2, 2021

ISSN: 2675-5254 — DOI: 10.21711/26755254/rmu202110

\title{
UM AGRADECIMENTO A SOPHIE GERMAIN
}

\author{
RIELI TAINÁ GOMES DOS SANTOS
}

\begin{abstract}
RESUMO. O artigo tem como objetivo relatar a história de uma jovem matemática inserida em uma sociedade extremamente patriarcal e suas tentativas em fazer parte do meio científico da época.
\end{abstract}

\section{INTRODUÇÃO}

É primavera na França, as flores estão desabrochando, as árvores recuperam suas folhagens. Juntamente ao clima agradável e quente, o clima revolucionário aflora. No poder está o monarca absoluto Luís XVI, este decidido a manter a sociedade francesa em camadas distintas e distantes: os privilegiados e o povo. A crise econômica permeia a França e o descontentamento com os gastos exacerbados por parte da nobreza é grande.

Além disso, o Iluminismo influencia as decisões, incitando a racionalidade, a importância do intelecto, o debate e as críticas. Na sociedade científica da época, o empirismo ganha forma e lugar. No entanto, as mulheres não eram permitidas nesse meio, tendo como função natural cuidar da casa e dos filhos.

Esse é o contexto do fim do século XVIII, mais especificamente do dia 1 de abril de 1776. Nesse dia nasce Sophie Germain em Paris. Mas o que há de tão especial nessa mulher?

\section{A Matemática}

Filha de pai burguês, um próspero comerciante, deputado e amigo de filósofos da época, Sophie vivenciou diversos debates políticos, ainda que não pudesse participar. À medida que se tornava adolescente, o encanto pelos números crescia. A sociedade

Data de aceitação: Setembro 2021.

Palavras chave. Sophie Germain, Mulheres na Ciência, História da Matemática.

A autora deste artigo gostaria de prestar agradecimento à professora Nincia Cecília Ribas Borges Teixeira (UNICENTRO) pela revisão ortográfica deste trabalho e ao corpo editorial, assim como aos pareceristas, pelas sugestões que possibilitaram uma melhora considerável deste artigo. 
patriarcal da época a proibia de se aprofundar nos assuntos da Rainha das Ciências. Ainda assim, ao anoitecer ia, escondida, para a extensa biblioteca do pai para ler.

O episódio que mais intrigou Sophie foi a morte de Arquimedes, retratada no livro Essais Historiques sur la Mathématique de Montucla, em que ele fora morto por um soldado romano por estar imerso em um problema de geometria. "O que há de tão interessante nessa área que valia mais que sua própria vida?", perguntou-se a menina. Posteriormente, esse evento a influenciaria na escolha da área matemática a seguir.

\section{A RevoluÇÃo}

Quando Sophie estava com 13 anos, a Revolução Francesa eclodiu. Dessa maneira, a rotina dos franceses foi drasticamente perturbada, assim como a da menina, que fora proibida de sair de casa. O ano de 1789 ficou conhecido como "O Grande Medo", com invasões frequentes a propriedades da aristocracia e o medo dos camponeses de ataques da nobreza. Como Sophie vinha de uma família burguesa, o medo se instalou.

Apesar da participação efetiva das mulheres na Revolução Francesa, foram lhes concedidos apenas direitos civis e nenhum direito político. Assim, a situação feminina na época continuava tensa e as mulheres ainda sofriam preconceito de gênero em certos ambientes tidos como masculinos.

A fim de entender melhor o contexto pós-revolução, Michelle Perrot afirma que:

A Revolução Francesa é, também, contraditória. O universalismo da Declaração dos direitos do homem e do cidadão não concerne verdadeiramente às mulheres: elas não são indivíduos. A Revolução lhes concede, no entanto, direitos civis, mas nenhum direito político. (Perrot, 2007, p. $142)$

Restava, então, para Sophie, planejar um modo de se inserir na sociedade científica da época a fim de aprofundar ainda mais seus conhecimentos na Matemática, já que era proibida de frequentar as academias.

\section{O Plano}

Para que pudesse receber cópias das anotações das aulas ministradas na École Polytechnique em Paris, Germain adotou o codinome de um ex-aluno: AntoineAuguste Le Blanc. Sophie estava particularmente interessada nas aulas de análise ministradas por Joseph-Louis Lagrange. Dessa maneira, ela poderia estudar os assuntos tratados nas aulas sem revelar sua verdadeira identidade.

$\mathrm{O}$ uso de codinomes masculinos apropriados por mulheres para adentrarem em ambientes masculinos era frequente até meados do século XX, quando os movimentos feministas ganharam força e as mulheres conquistaram o direito de serem ouvidas. Então, no século XVIII, suas vozes ainda eram silenciadas e, para que fossem ouvidas, deveriam usar como meio as vozes masculinas, como retrata Londa Schiebingir: "Mesmo a grande feminista inglesa Mary Wollstone-craft, em seus esforços para criar igualdade entre os sexos, encorajava as mulheres a tornarem-se 'mais masculinas e respeitáveis'." (Schienbinger, 2001, p. 138) 


\section{A RevelaÇÃo}

Os professores da École Polytechnique tinham por costume motivar os alunos a enviarem observações escritas sobre os conteúdos tratados nas aulas expositivas. Germain, então, enviou suas anotações a Lagrange que, desconfiado da rápida melhora acadêmica de Antoine-Auguste Le Blanc, solicitou uma entrevista com o ex-aluno e Sophie obrigou-se a revelar sua verdadeira identidade. Devido a sua genialidade na área, o professor a incentivou a dar continuidade em seus estudos e começou a orientá-la.

A figura marcante de Sophie no cenário matemático da época, devido à constatação feita por Lagrange de que seus trabalhos eram de alta qualidade, atraiu a curiosidade de diversos estudiosos, ansiosos para enviarem seus estudos para a cientista e conversarem sobre suas pesquisas. Germain estava inserida direta e indiretamente no campo científico parisiense e tendo como importantes mentores Lagrange e Legendre.

Quando Legendre, em 1798, publicou um resumo sobre sua pesquisa intitulado Essai sur la théorie des nombres, a cientista leu e veio a se interessar pela Teoria dos Números. Decidiu, portanto, enviar uma carta ao grande matemático dessa área, C. F Gauss, com suas observações pessoais, em especial acerca o Último Teorema de Fermat. É claro que o medo de ser julgada por seu gênero a fez assinar as cartas com seu codinome. Ao perceber a determinação e talento de Germain, Gauss respondeu à matemática. A troca de cartas entre os cientistas ficou cada vez mais frequente.

As cartas entre os cientistas perduraram por anos sem que Gauss soubesse a verdadeira identidade de Germain. No entanto, em 1806, o imperador Napoleão Bonaparte invadiu a Prússia e Sophie, temendo pela morte de Gauss, pediu ao General Pernety, amigo próximo da família, que garantisse a segurança do cientista. O general disse a Gauss que agradecesse a "Mademoiselle Germain". Mas quem seria ela? Nunca havia escutado esse nome antes.

Posteriormente, Germain enviou uma carta ao matemático revelando sua identidade e aquele a respondeu com uma magnífica carta a agradecendo e reconhecendo seu trabalho e determinação. Essa carta está presente em Germain and Stupuy, 1896.

Em meados de 1830, Gauss convenceu a Universidade de Göttingen a homenagear Germain com um título honorário, feito inédito para uma mulher, no entanto, Sophie faleceu antes de aceitar o título devido a um câncer nas mamas.

\section{ContribuiçÕes Científicas}

Sophie foi de extrema importância para a Física. Na Alemanha, Chladni havia feito experimentos sobre as vibrações de membranas elásticas, os quais tiveram resultados muito curiosos. Dessa forma, o cientista visitou Paris, em 1808, a fim de reproduzir tais experimentos. Seu método consistia em despejar areia fina sobre uma placa que vibrava e, à vista disso, padrões eram formados de acordo com as vibrações produzidas. Durante esse período, a teoria matemática acerca dos movimentos de vibração unidimensionais estava completa, mas surgia a necessidade de estender os estudos para as vibrações em superfícies elásticas. Napoleão, líder militar da época, 
instigou a Academia de Ciências a abrir uma competição para incentivar a procura de uma explicação matemática para esse problema.

Sophie decidiu participar da competição e submeteu anonimamente sua teoria matemática acerca das vibrações das membranas elásticas, em 21 de setembro de 1811. No entanto, devido ao fato de Germain não possuir um curso formal em Análise, a equação das superfícies elásticas fornecida por ela estava com imprecisões e a questão ainda estava em aberto. A Academia, então, abriu pela segunda vez a competição e Sophie estudou mais profundamente sobre o assunto e, em 23 de setembro de 1813, submeteu novamente seu trabalho, ainda com imprecisões, como relata Legendre em uma carta enviada a Sophie em 4 de dezembro de 1813:

Não entendo nada, na análise que você está me enviando, certamente, há um erro de redação ou de raciocínio. [...] Se a comissão do Instituto fosse dessa opinião, você poderia ser mencionada com honra; mas temo que a análise fracassada prejudique seriamente a dissertação, apesar do que ela pode conter de bom. (Laubenbacher and Pengelley, 2010)

E foi o que realmente ocorreu, Sophie recebeu apenas uma menção honrosa.

A competição foi estendida novamente e, com mais confiança, Germain abandonou o anonimato. Dessa vez, o trabalho da cientista foi premiado, apesar de ainda ser criticado como incompleto. Sophie, com sua personalidade reservada, não compareceu a premiação pública, onde o prêmio foi anunciado.

Com o conhecimento vasto acerca dessas áreas da Física, auxiliou nos cálculos para a construção da Torre Eiffel. No entanto, a cientista não recebeu o reconhecimento merecido por esse feito. Na lista de agradecimento aos matemáticos que ajudaram na construção da Torre, o nome de Sophie não aparece dentre os 72 nomes incluídos na lista, todos masculinos.

Além disso, Germain contribuiu fortemente para a área de Teoria dos Números. A Academia de Ciências abriu uma nova competição para a prova do Último Teorema de Fermat (UTF) e, apesar da cientista nunca ter publicado sobre esse assunto, é conhecido que ela estudou os teoremas não demonstrados por Fermat devido aos créditos dados a ela em uma segunda edição do ensaio de Théorie des Nombres de Legendre. Porém, o resultado creditado a cientista nesse ensaio, conhecido hoje como Teorema de Germain, é uma pequena parte do trabalho de Sophie na tentativa de provar o UTF. Ademais, estudou sobre certos números com propriedades especiais, denominados, posteriormente, de Primos de Germain. Mas o que têm de tão especiais?

Primeiramente, vamos enunciar o Último Teorema de Fermat. Este afirma que não existem $x, y, z \in \mathbb{N}$, todos não-nulos, que satisfaçam a seguinte equação:

$$
x^{n}+y^{n}=z^{n}
$$

em que $n>2$ e $n \in \mathbb{N}$.

O Primeiro Caso do UTF afirma que:

$$
x^{n}+y^{n}=z^{n}
$$

é impossível em inteiros não divisíveis por $n$. 
Um número primo de Germain $p$ é assim chamado quando $2 p+1$ é também primo. Temos, como exemplos, os números 2, 3, 5, 11, 23, 29, etc. A infinitude desses números é até hoje desconhecida, sendo titulada como uma conjectura. Os Primos de Germain conquistaram tamanha notoriedade, pois o Primeiro Caso do UTF é válido para $n=p$, onde $p$ é um primo de Germain. Nesse momento, havia apenas provas para $n=4$, demonstrada pelo próprio Fermat, e para $n=3$, demonstrada por Euler.

Teorema 6.1 (Teorema de Germain). Seja p um primo impar. Se existe um primo auxiliar $q$ com as seguintes propriedades:

(1) $x^{p}+y^{p}+z^{p} \equiv 0(\bmod q)$ implica $x=0$ ou $y=0$ ou $z=0(\bmod q) e$

(2) $a^{p} \equiv p(\bmod q)$ é impossivel para qualquer inteiro a,

então o Caso 1 do Último Teorema de Fermat é válido para p.

Uma prova para esse teorema pode ser encontrada em Martinez et al. 2018.

Em 1823, Sophie compartilhou esse teorema com Legendre. Ela havia encontrado primos auxiliares para todos os primos menores que 100, exceto para o 2. Legendre extendeu o teorema de Germain para primos auxiliares das formas $q=4 p+1,8 p+$ $1,10 p+1,14 p+1$ ou $16 p+1$. Além disso, o cientista provou que o teorema não seria válido quando $q=(m n+1)$ se $m$ fosse divisível por 3. Assim, foram encontrados primos auxiliares $q$ para todos os primos menores que 197, provando, portanto o Caso 1 do UTF para todos esses primos. Ademais, todas essas descobertas foram feitas antes mesmo da prova para o caso em que $n=5$.

Os Primos de Germain são de grande importância, pois contribuíram fortemente para diversos avanços nas provas do Primeiro Caso do UTF. Em 1908, Leonard Dickson, generalizando o Teorema de Germain, provou o Primeiro Caso do UTF para todos os primos menores que 7.000 e J. Rosser, em 1940, utilizando também a generalização, provou o Primeiro Caso para todos os primos menores que 41.000.000.

\section{A Filósofa}

Além do encanto da cientista pelas ciências exatas, sua infância, situada no fervor dos ideais revolucionários do século XVIII, influenciou no seu futuro interesse pela filosofia científica, ao ouvir diversos debates em que seu pai participava. Ademais, Sophie era uma leitora ávida de poemas e era encantada pela música.

Sophie escreveu dois trabalhos filosóficos: Pensées Diverses, o qual é uma coleção de breves reflexões acerca de diversos assuntos e Considérations générales sur l'état des sciences et des lettres aux différentes époques de leur culture, no qual a filósofa trata das conexões existentes entre a arte e a ciência por meio da história do desenvolvimento intelectual humano. Germain apresenta, nessa última obra, as similaridades entre trabalhos científicos e artísticos, os quais devem seguir certas regras para que sejam considerados belos.

Por exemplo, a uma primeira vista, cálculo e poesia parecem distintos em todos os aspectos, mas perceba que ambos são inspirados por uma ideia de proporção e ordem e suas escritas necessitam de certo estilo para que a mensagem seja devidamente transmitida. De acordo com Germain, ciência e arte são ambas inspiradas pela procura de uma verdade universal por meio da ordem e da simplicidade. Além 
disso, Sophie discute sobre o início da atividade intelectual humana e discorre acerca da linguagem, a qual foi inventada para comunicação, mas no decorrer do desenvolvimento humano, foi utilizada para discutir ideias abstratas e novas palavras foram criadas, sem uma definição precisa. É por esse motivo, segundo ela, que uma mesma frase possui uma infinidade de interpretações diferentes. Assim, para Sophie, a Matemática era a única linguagem que não causava essa confusão e apresentava ao ser humano uma realização da verdade.

A escola filosófica de Diderot, ao procurar explicar as similaridades entre ciência e arte, deixou de focar apenas nas causas do fenômeno, isto é, nos "porquês"e passou a se perguntar "como?". Nos escritos de Sophie, é possível perceber a relação próxima de suas reflexões com a escola de Diderot e, também, de Condorcet.

Suas obras não foram publicadas enquanto estava viva e certamente não foram escritas para tal fim, pois tratavam-se, em sua maioria, de notas e reflexões isoladas. Seu sobrinho, Armand-Jacques Lherbette, como forma de homenagem a memória de Sophie, em 1833, compilou e imprimiu suas reflexões filosóficas. Em 1879, esses escritos foram republicados em uma obra titulada Oeuvres philosophiques de Sophie Germain (Germain and Stupuy 1896), contendo também correspondências da cientista e sua bibliografia por Hippolyte Stupuy. A obra Considérations foi elogiada por Auguste Comte, fundador da filosofia positivista, e influenciou posteriormente em suas reflexões.

\section{Agradecimento}

Dessa maneira, pode-se perceber o preconceito gritante que havia na época quanto aos lugares ocupados pelas mulheres. Sabendo das dificuldades enfrentadas pela matemática, venho agradecer a persistência dessa incrível mulher em estudar e aprofundar-se em assuntos tão inalcançáveis para as mulheres de sua época. Com toda certeza, seus progressos na Matemática e na Física impactam a ciência como um todo nos dias de hoje. Seus estudos acerca da elasticidade permitiram avanços em grandes construções na engenharia e seus estudos em Teoria dos Números auxiliaram diversos matemáticos.

Além disso, agradeço a Germain pela inspiração para encontrar a voz feminina em um mundo tão masculino. As estatísticas quanto à participação feminina nas ciências exatas melhorou muito, mas ainda é preocupante. Precisamos conhecer mais mulheres como Germain, que deram o primeiro passo para uma equidade de gênero no meio científico, assim como no meio social.

\section{REFERÊNCIAS}

A. D. Centina and A. Fiocca. The correspondence between Sophie Germain and Carl Friedrich Gauss. Archive for History of Exact Sciences, 66(6):585-700, nov 2012. ISSN 1432-0657. doi: 10.1007/s00407-012-0105-x. URL https://doi .org/ 10.1007/s00407-012-0105-x.

S. Germain and H. Stupuy. Oeuvres philosophiques de Sophie Germain ; suivies de pensées et de lettres inédites. Et précédées d'une notice sur sa vie et ses oeuvres (Nouv. éd.) / par Hte Stupuy. 1896. URL https://gallica.bnf.fr/ark: /12148/bpt6k2032890. 
A. Granville and M. B. Monagan. The first case of fermat's last theorem is true for all prime exponents up to 714,591,416,091,389. Transactions of the American Mathematical Society, 306(1):329-359, 1988. ISSN 00029947. URL http://www. jstor.org/stable/2000841.

N. Hall, M. Jones, and G. Jones. A Vida e o Trabalho de Sophie Germain. pages 32-35, jan 2004. URL <http://gazeta.spm.pt/getArtigo?gid=89.

A. M. Hill. Sophie Germain: a mathematical biography. University of Oregon, 1995.

L. Kelley. Why Were So Few Mathematicians Female? The Mathematics Teacher, 89(7):592-596, 1996. ISSN 0025-5769. URL https://www.jstor.org/stable/ 27969922. Publisher: National Council of Teachers of Mathematics.

R. Laubenbacher and D. Pengelley. "Voici ce que j'ai trouvé:" Sophie Germain's grand plan to prove Fermat's Last Theorem. Historia Mathematica, 37(4):641692, Nov. 2010. ISSN 0315-0860. doi: 10.1016/j.hm.2009.12.002. URL https: //www.sciencedirect.com/science/article/pii/S0315086009001347.

F. Martinez, C. G. Moreira, N. Saldanha, and E. Tengan. Teoria dos Números um passeio com primos e outros números familiares pelo mundo inteiro. IMPA Instituto de Matemática Pura e Aplicada, 5rd edition, 2018. ISBN 978-85-2440447-4.

M. Perrot. As mulheres ou os silêncios da história. EDUSC, Bauru, SP, 2005. ISBN 85-7460-251-5. Tradução: Viviane Ribeiro.

M. Perrot. Minha historia das mulheres. Contexto, São Paulo, 2007. ISBN 978-857244-348-7. Translation: Angela M. S. Côrrea.

L. Saya. O Clima Revolucionário na França do Século XVIII: politização, descristianização e o impacto nas instituições sociais. pages 1-13, 2016.

L. Schienbinger. O feminismo mudou a ciência? EDUSC, Bauru, SP, 2001. ISBN 85-7460-063-6. Tradução: e Raul Fiker.

I. Stewart and D. Tall. Algebraic Number Theory and Fermat's Last Theorem. 3rd edition, 1945. ISBN 1568811195. doi: 10.1201/b19331.

Universidade Estadual do Centro-Oeste - PR

Email address: rielitaina@outlook.com 